\title{
A bold move to regulate tobacco products
}

My wife's father, Dr C Dixon Fowler, died the day before I wrote this editorial. He was a brilliant and cheerful man. He practiced pediatrics in Atlanta for decades and, with his wife Mary, he raised three wonderful daughters. Dixon had smoked cigarettes for more than 60 years, having been unable to stop despite many attempts. Debilitated by years of emphysema and chronic bronchitis, lung cancer finally caught up with him. He had his last smoke, a Doral, a few days before his death.

Dixon smoked Lucky Strike ("Do you inhale? What's there to be afraid of?") until the mid-1950s when, in the midst of the cancer scare, he changed to Viceroy ("The thinking man's filter"). In recent years, he had switched to brands that sold at bargain prices. He regretted ever having started smoking, but he could not stop. He was addicted to nicotine.

Dixon is one of hundreds of thousands who will die in the United States this year because of cigarettes. The government's failure to prevent many if not most of these deaths is a tragic chapter in the history of public health. However, recent events suggest that the era of inaction and ineffectual action may be drawing to a close.

On 25 February 1994, Dr David A Kessler, Commissioner of the US Food and Drug Administration (FDA), wrote the Coalition on Smoking OR Health that evidence was accumulating that cigarette manufacturers may intend to addict at least some of their customers to nicotine. ${ }^{1} \mathrm{Dr}$ Kessler declared that if this were proven, it could form a basis for FDA regulation of cigarettes that contain addicting levels of nicotine. A month later, $\mathrm{Dr}$ Kessler elaborated on this suggestion in testimony before Congress. That dramatic testimony is reproduced in this issue of Tobacco Control beginning on page 148.

Dr Kessler's letter and testimony may turn out to be the most important developments in tobacco control since the 1964 report of the Surgeon General's Advisory Committee. ${ }^{2}$ The 1964 report focused national attention on the problem of lung cancer from smoking and led to warning labels on packs and in advertising and to the ban on most broadcast advertising for cigarettes. However, by 1971, the energy generated by the 1964 report had largely been spent. In the years since, an enormous body of evidence has accumulated on the harm caused by tobacco, on the addictive nature of nicotine, and on productive ways public health can respond to these challenges. ${ }^{3-6}$ Despite all this knowledge, government has so far failed to take action commensurate with the scope of the problem. Dr Kesgler's letter and testimony present a new paradigm for dealing with this problem and offer new hope for public health.

At the heart of Dr Kessler's approach is the legal concept of "drug". Under the Food, Drug and Cosmetic Act, a drug is an article described in an official compendium, such as the US Pharmacopeia; an article intended by the manufacturer to cure, mitigate, treat or prevent disease; or an article (other than food) intended by the manufacturer to affect the structure or a function of the body. The manufacturer's intended use of the article is of central importance in this definition. If tobacco product manufacturers intend that their products affect the structure or a function of the body, these products can be treated as drugs under the law.

The Food, Drug and Cosmetic Act is very specific, however, in its directions to the FDA about how the agency must regulate drugs. The FDA can only permit drugs on the market that are of demonstrated safety and efficacy. In the absence of either safety or efficacy data, a drug cannot be approved for sale. The application of the Act in its present form to tobacco products that contain addicting levels of nicotine would lead to their prohibition because none are safe. Pointing to several major disadvantages of prohibition, the acute difficulties of abrupt withdrawal created for the millions addicted to nicotine and the creation of a black market in tobacco products, the Commissioner has asked Congress for help in developing a regulatory structure which would address the problem without forcing a ban on the products. ${ }^{1}$ This assistance, if it is forthcoming, might take the form of an amendment to the Food, Drug and Cosmetic Act giving tobacco products quasi-drug status, permitting drug-like regulation while not banning tobacco products outright. ${ }^{7}$ Another possible approach is the imposition of a declining ceiling on the maximum nicotine content in a tobacco product. Under this approach, the only tobacco products that would eventually be permitted on the market would have nicotine levels below those necessary to create or sustain addiction. US News and World Report has reported that if Congress fails to act, the FDA may rule cigarettes unsafe and phase in a ban, giving Congress another opportunity to pass appropriate legislation. ${ }^{8}$

The idea that tobacco products can be regulated as drugs is neither new nor novel. What is new is the breadth of the Commissioner's analysis and the sweep of his vision. Up to now, the FDA has only regulated tobacco products on a case-by-case basis.

The FDA first asserted regulatory authority over a tobacco product in 1952 when it declared a brand called Fairfax to be a drug. ${ }^{9}$ Advertising for Fairfax proclaimed its utility in preventing respiratory diseases, scarlet fever, meningitis, mumps, and psittacosis and declared the product "innocuous" for individuals with cardiovascular disease. ${ }^{10}$ The FDA decided that these health claims made the brand a drug. The brand is still marketed, although its marketer abandoned these health claims as a result of the FDA action. In 1958, the FDA took action against Trim Reducing-Aid Cigarettes because of the claim that a patented ingredient helped with weight reduction. ${ }^{11}$ In the 1980 s, the agency classified two other tobacco products as drugs, Favor and N-Bloctin/Spectra. ${ }^{12,13}$ Favor, a nicotine inhaler, was classified as a drug based on the manufacturer's claims that the product was useful in maintaining an individual's dependence on nicotine. Spectra contained $\stackrel{\oplus}{\stackrel{\oplus}{+}}$ an additive, N-Bloctin, that was alleged to reduce the absorption of carcinogens. Finally, the FDA classified a $\frac{O}{D}$ tobacco-containing chewing gum, Masterpiece Tobacs, as a food product and ordered it removed from the market $\stackrel{\square}{2}$ because tobacco was not (and still is not) an approved additive for foods. ${ }^{14}$

Premier, a novel nicotine delivery device developed by the RJ Reynolds Tobacco Company, was withdrawn from test markets before the FDA made a decision on whether or not to regulate it. ${ }^{15}$

There have been a number of attempts in the past to encourage the FDA to become more broadly involved in tobacco product regulation. Action on Smoking and Health (ASH) petitioned and sued the FDA in the 1970s 
in an unsuccessful effort to force the agency to regulate cigarettes as drugs. ${ }^{16}$ Since 1988 , the Coalition on Smoking OR Health has submitted a series of petitions to the FDA about health claims implicit in the advertising for the socalled low-tar cigarettes and in the weight-reduction claims of brands targeted at women. ${ }^{17,18}$ These petitions had gone unanswered until recently. The approach used by the FDA, with its focus on nicotine and addiction, is quite different from that envisioned in the Coalition's petitions.

The task before the FDA is enormous, but it is achievable. ${ }^{19}$ The tobacco industry is expert at concealment. The FDA must expose layer upon layer of euphemism and secrecy to build a case that tobaccoproduct manufacturers intend to maintain an addiction to nicotine among their best customers. Dr Kessler's statement to Congress shows that FDA is serious about pursuing this and that the agency is willing to commit the resources necessary to develop the case.

The task before Congress is no less formidable because of the enormous political influence the industry possesses, but it, too, is achievable. To avoid the prospect of tobacco prohibition, Congress must develop a credible regulatory structure which will control this enormous problem.

The task for the public health community is to support FDA and those in Congress who seek to give FDA specific authority in this area. It has taken decades to get this issue squarely into the regulatory arena where it has always belonged. Now that it is there, we will have to work very hard over the next several years to develop an adequate regulatory structure for tobacco products. Once the structure is built, we will have to make it work.

It is too late for Dixon and for the other millions who have already died, but it is not too late for the millions who are still addicted to nicotine and for the millions who, in the absence of appropriate regulation, will become addicted to nicotine. ${ }^{20}$

\section{St Peter's Medical Center, UMDNF-Robert Wood fohnson Medical School, New Brunswick, New fersey, USA}

This work was supported in part by a grant from the Robert Wood Johnson Foundation.
1 US Food and Drug Administration. Letter from David A Kessler Commissioner of FDA, to Scott Ballin, Coalition on Smoking OR Health Commissioner of FDA, to Scott Ballin,

2 US Department of Health, Education, and Welfare. Smoking and health. Report of the Advisory Committee to the Surgeon General of the Public Health Service. US Department of Health, Education, and Welfare, Public Health Service, 1964. (PHS Publication No 1103.)

3 US Department of Health and Human Services. The health consequences of using smokeless tobacco. A report of the Advisory Committee to the Surgeon General. US Department of Health and Human Services, Public Health Service, 1986. (NIH Publication No 86-2874.)

4 US Department of Health and Human Services. The health consequences of smoking: nicotine addiction. A report of the Surgeon General, 1988 Washington, DC: US Department of Health and Human Services, Public Health Service, Centers for Disease Control, National Center for Chronic Disease Prevention and Health Promotion, Office on Smoking and Health, 1988. (DHHS Publication No (CDC) 88-8406.)

5 US Department of Health and Human Services. Reducing the health consequences of smoking: 25 years of progress. A report of the Surgeon General, 1989. Atlanta, Georgia: US Department of Health and Human Services, Public Health Service, Centers for Disease Control, Nationa Center for Chronic Disease Prevention and Health Promotion, Office on Smoking and Health, 1989. (DHHS Publication No (CDC) 89-8411)

6 Houston TP, ed. Tobacco use: an American crisis. Final report of the conference. Washington, DC: American Medical Association, 1993.

7 Synar M. HR 2147, Fairness in Tobacco and Nicotine Regulation Act Washington, DC: US House of Representatives, 1993.

8 Brownlee S, Roberts SV. Should cigarettes be outlawed? US News and World Report, 18 April 1994: 32-8.

9 United States $v 46$ Cartons... Fairfax Cigarettes, 113 F Supp 336 (DNJ 1953).

10 United States $v 46$ Cartons... Fairfax Cigarettes, Libel of Information, FDC No 33295, 1952

11 United States $v 354$ Bulk Cartons Trim Reducing-Aid Cigarettes, 178 F Supp 847 (DNJ 1959).

12 US Food and Drug Administration. Letter from Daniel L Michels, Director, Office of Compliance, Center for Drugs and Biologics, to Philip Ray, Advanced Tobacco Products, Inc (San Antonio, Texas), 9 February 1987.

13 US Food and Drug Administration. Letter from Daniel L Michels, Director, Office of Compliance, Center for Drugs and Biologics, to L Douglas Keeney, CA Blockers Inc (Louisville, Kentucky), 14 April 1989.

14 US Food and Drug Administration. Letter from Richard J Ronk, acting director, Center for Food Safety and Applied Nutrition, to Stuart Pape, director, Center for Food Safety and Applied Nutrition, to Stuat
Patton, Boggs \& Blow (Washington, DC), 16 September 1987.

15 Slade J. Nicotine delivery devices. In: Orleans CT, Slade J, eds. Nicotine addiction: principles and management. New York: Oxford University

16 Action on Smoking and Health $v$ Harris, 655 F 2d 236 (DC Cir 1980).

17 Coalition on Smoking OR Health. Petition to classify low "tar" cigarettes as "drugs" under the Food, Drug and Cosmetic Act, Washington, DC, 9 April 1988

18 Coalition on Smoking OR Health. Petition to classify cigarette products which are manufactured, advertised, promoted and labelled with implied or direct claims that use of these products will suppress appetite and control weight "duse " under products will suppress appetite and Washington, DC, 27 February 1992 .

19 Slade J, Connolly GN, Davis RM, et al. Report of the tobacco policy research study group on tobacco products. Tobacco Control 1(suppl): S4-S9, 1992.

20 US Department of Health and Human Services. Preventing tobacco use among young people. A report of the Surgeon General. Atlanta, Georgia: US Department of Health and Human Services, Public Health Service, Centers for Disease Control and Prevention, National Center for Chronic Disease Prevention and Health Promotion, Office on Smoking and Health, 1994 